This is the postprint version of the article published as Part. Part. Syst. Charact., 33: 412-418. doi:10.1002/ppsc.201600037

\title{
WILEY-VCH
}

DOI: 10.1002/ ((please add manuscript number))

Article type: Full paper

\section{Assessing Photocatalytic Activity at the Nanoscale using Integrated Optical and Electron Microscopy}

Elke Debroye, Jordi Van Loon, Xian Gu, Thomas Franklin, Johan Hofkens, Kris P. F. Janssen, * Maarten B. J. Roeffaers*

$$
\text { . }
$$

Dr. E. Debroye, X. Gu, Prof. J. Hofkens, Dr. K. P. F. Janssen

Formatted: Dutch (Belgium)

Department of Chemistry, Laboratory for Photochemistry and Spectroscopy, KU Leuven,

Celestijnenlaan 200F, B-3001 Leuven, Belgium

E-mail: kris.janssen@chem.kuleuven.be

Drs. J. Van Loon, Dr. T. Franklin, Prof. M. B. J. Roeffaers

Department of Microbial and Molecular Systems, Centre for Surface Chemistry and Catalysis, KU Leuven, Celestijnenlaan 200F, B-3001 Leuven, Belgium

E-mail: maarten.roeffaers@biw.kuleuven.be

Keywords: photocatalysis, zinc oxide, dynamic study, liquid cell, integrated optical-electron microscopy

An integrated optical-electron microscope is presented that enables the in situ study of dynamic processes on photo-active materials. Here, the deposition of metallic silver nanostructures at $\mathrm{ZnO}$ photocatalyst particles is monitored in real time under ambient conditions by means of scanning electron microscopy. Zinc oxide crystals are immobilized on an electron transparent silicon nitride window. By passing UV light through an opposing optically transparent window, the zinc oxide is illuminated resulting in the photocatalytic formation of silver nanostructures. Both windows are part of a specially designed liquid cell filled with a dilute aqueous silver nitrate solution. Using the presented system, different electron detectors are evaluated for their ability to provide detailed images despite the interference caused by the liquid surrounding the sample. Special care has to be taken since direct silver reduction from solution induced by the electron beam interferes with the photocatalytic process. Oxygen gas, produced during to the photocatalytic reaction, is shown to also complicate the imaging of the dynamic nanoscale processes in the SEM. Nevertheless, 
This is the postprint version of the article published as Part. Part. Syst. Charact., 33: 412-418. doi:10.1002/ppsc.201600037

\section{WILEY-VCH}

the integrated approach allows to directly establish structure-activity relationships and to unravel optically induced processes at nanostructured materials.

\section{Introduction}

Research into nanomaterials is strongly driven by their unique functional properties which strongly depend on size, morphology, organization and composition. As such, electron microscopy has become an indispensable research tool for studying nanoparticles, as it allows detailed structural characterization at relevant length scales. At this moment however, it is not yet possible to directly link this detailed structural information to the functioning of the nanomaterials at the same length scale.

Heterogeneous nano-photocatalysts show promising results at the laboratory scale for applications in environmental remediation, as well as in the generation of fuels and organics. ${ }^{[1]}$ There is evidence that the performance of photocatalytic nanomaterials is be correlated to the structural and morphological features of individual catalyst particles. ${ }^{[2-4]}$ Recently, we have reported on a simple method to generate dendritic silver nanostructures at the surface of $\mathrm{ZnO}$ crystals via the UV induced photocatalytic reduction of silver ions from an aqueous $\mathrm{AgNO}_{3}$ solution (Figure $\mathrm{S} 1$ ). ${ }^{[5]}$ These nanometer sized silver structures act as an efficient electron sink, rendering the dendrites into potential co-catalysts. ${ }^{[6-8]}$ It is believed that the nucleation and growth of these silver dendrites is subject to intra- and inter-particle heterogeneities. ${ }^{[6,8-10]}$ To investigate the photodeposition dynamically at the single photocatalyst particle level, an optical microscope is integrated into a scanning electron microscope (SEM) by means of a custom-made SEM chamber door (Secom, Delmic BV). This integrated instrument allows the in situ SEM observation and quantitative analysis of the deposition of silver co-catalysts under UV illumination. A crucial step towards this in situ observation is the development of a liquid cell that is equipped with both an electron and 
This is the postprint version of the article published as Part. Part. Syst. Charact., 33: 412-418. doi:10.1002/ppsc.201600037

\section{WILEY-VCH}

optically transparent windows, while it is compatible with the reduced pressure in the sample chamber of the electron microscope. The general advantage of the developed wet sample holder for electron microscopy is the ability to image structural changes of materials under optical stimulation while keeping the samples under realistic conditions, i.e. atmospheric pressure and even wet conditions. Dynamic processes, in this study occurring at the photocatalyst surface under UV illumination, can as such be investigated with nanometerscale detail provided by SEM. A similar sample holder was also used recently to image biological specimen simultaneously in fluorescence and electron microscopy. ${ }^{[1]}$

\section{Integrated light- and electron microscopy}

The integrated light- and electron microscope used in this research consists of a FEI Quanta 250 FEG environmental SEM, equipped with the SECOM platform provided by Delmic BV (Figure 1a). ${ }^{[12,13]}$ This configuration allows $365 \mathrm{~nm}$ UV light from an LED source (Thorlabs) outside of the vacuum chamber, to be coupled in via an optically transparent window (Figure 1b). Inside the vacuum chamber (Figure 1c), a high NA objective lens (Nikon Plan APO VC 100x, 1.4 NA) enables sample illumination from the bottom, i.e. opposite to the electron gun located above the sample. Such a configuration allows to study in situ the photodeposition of metallic silver nanoparticles at the $\mathrm{ZnO}$ photocatalysts in an SEM. The possibility of conducting these experiments in one and the same setup implies that sample contamination or alteration can be minimized since there is no need for shuttling the sample between dedicated setups. As to enable the in situ investigation, a dedicated liquid cell has been developed (Figure 1d) to allow the immersion of the photocatalytic material in an aqueous silver nitrate solution while inside the vacuum of the SEM sample chamber. This liquid cell consists of a glass cover slip at the bottom and a $50 \mathrm{~nm}$ thick electron transparent $\mathrm{Si}_{3} \mathrm{~N}_{4}$ window (Silson 
This is the postprint version of the article published as Part. Part. Syst. Charact., 33: 412-418. doi:10.1002/ppsc.201600037

\section{WILEY-VCH}

Ltd.) at the top of the cell. Both windows are held together by two metal plates that are separated by an O-ring to ensure proper sealing and spacing, resulting in a cell volume of 50 $\mu \mathrm{L}$. The photocatalyst material is deposited on the $\mathrm{Si}_{3} \mathrm{~N}_{4}$ surface facing the inside of the liquid cell, where it is submersed in the reagent solution if the cell is completely filled. In this approach, the integrated optical microscope enables to restrict the photo-stimulation of $\mathrm{ZnO}$ crystals to the field of view. Without this spatial control, and while maintaining the same UV photon flux, photocatalyst activation and oxygen formation would be induced on all $\mathrm{ZnO}$ crystals, including those outside the field of view. With this setup it is certainly possible to directly correlate optical images to the detailed scanning electron micrographs. As illustration, optical transmission images of silver nanostructures photo-deposited on $\mathrm{ZnO}$ particles can be consulted in Fig. S3 in the Supporting Information. Clearly, the amount of detail resolved in the SEM images clearly surpasses the typical diffraction limited optical images.

During imaging in the liquid cell, the electron beam has to pass through a $50 \mathrm{~nm}$ thick $\mathrm{Si}_{3} \mathrm{~N}_{4}$ window in order to reach the sample surface. This will lead to increased electron scattering and decreasing signal to noise ratio, hence, resolution loss is inevitable. ${ }^{[14,15]}$ Image resolution for different imaging modes is typically investigated using gold nanoparticles dispersed on a $\mathrm{Si}_{3} \mathrm{~N}_{4}$ window, as has been discussed for biological samples by Liv et al. ${ }^{[11]}$ This study led to the general conclusion that back scattered electron detection (BSED) at $20 \mathrm{kV}$ is mostly suited to obtain the highest possible resolution in the lateral dimension. By using small-sized gold nanoparticles, however, no information on the axial resolution is obtained. Furthermore, as biological samples are mostly composed of organic structures, contrast differentiation based on the atomic weight is limited compared to higher atomic number elements typically making up inorganic samples. As such, there is limited information concerning the effect of different SEM detectors on the axial imaging performance on semiconductor materials as used in this 
This is the postprint version of the article published as Part. Part. Syst. Charact., 33: 412-418. doi:10.1002/ppsc.201600037

\section{WILEY-VCH}

work. In Figure 2 a-c, a comparison between the imaging capacity of a BSED, an Everhart-

Thornley Detector (ETD) and a Gaseous Secondary Electron Detector (GSED) is made for an ensemble of $\mathrm{ZnO}$ particles deposited below the $50 \mathrm{~nm}$ thick $\mathrm{Si}_{3} \mathrm{~N}_{4}$ window. These images are obtained with a $20 \mathrm{kV}$ acceleration voltage and spot size 4, in the absence of liquid. Note that the GSED image (Figure 2c) is captured at an increased chamber pressure of 2 mbar. When targeting structural features close to the $\mathrm{Si}_{3} \mathrm{~N}_{4}$ window, the resolution obtained with all three detectors is very similar. However, the ETD and GSED images rapidly become blurry with increased imaging depth, whereas crystal features further away from the $\mathrm{Si}_{3} \mathrm{~N}_{4}$ window remain sharp in the BSED image. For example, based on the shape and dimensions of the central $\mathrm{ZnO}$ crystal, it can be estimated that the crystalline structures highlighted with the gray circles in Figure 2 a-c are located approximately $2.4 \mu \mathrm{m}$ below the $\mathrm{Si}_{3} \mathrm{~N}_{4}$ window. Clearly, these structures are best resolved in Figure 2a, which corresponds to previous findings that the BSED detector is preferred for imaging through a $\mathrm{Si}_{3} \mathrm{~N}_{4}$ window although the differences are minimal. The more pronounced resolution loss at extended imaging depths in secondary electron (SE) images compared to BSE images can be explained by a combined effect of the higher absorption of low energy secondary electrons by the $\mathrm{Si}_{3} \mathrm{~N}_{4}$ window and the general decreased signal that is generated from lower lying structures.

The structures in direct contact with the $\mathrm{Si}_{3} \mathrm{~N}_{4}$ window in Figure 2 a-c show signs of charging at the $\mathrm{ZnO}$ crystals, as the detector signal is locally saturated. This charging will be effectively reduced once the sample holder is filled with liquid. The presence of a liquid, water in these experiments, will however in its turn lead to increased scattering. Therefore, in the next step, the effect of an aqueous reagent solution on the imaging quality in the liquid cell is investigated. In Figure 2d, a mounted liquid cell is shown in which a major part of the $\mathrm{ZnO}$ 
This is the postprint version of the article published as Part. Part. Syst. Charact., 33: 412-418. doi:10.1002/ppsc.201600037

\section{WILEY-VCH}

crystals is submersed in the aqueous solution, e.g. inset (1). Clearly, only structures that are in close contact with the $\mathrm{Si}_{3} \mathrm{~N}_{4}$ surface can be imaged. A fraction of the $\mathrm{ZnO}$ particles are, however, still contained within residual air pockets, e.g. inset (2), and are characterized by an increased imaging depth. This example clearly demonstrates the exact effect of drastically increased electron beam scattering on the imaging quality. Despite the inherent loss of imaging depth when samples are effectively submersed in a liquid, the crystal areas within close vicinity of the $\mathrm{Si}_{3} \mathrm{~N}_{4}$ window can still be observed at the nanoscale. Further, air pockets underneath the $\mathrm{Si}_{3} \mathrm{~N}_{4}$ window need to be avoided if the photocatalytic silver deposition is to be quantitatively investigated.

\section{Impact of electron beam}

It has been reported that electron beam irradiation can initiate metal deposition on both semiconductors and non-conductive surfaces by the direct reduction of metal ions even in absence of a photocatalysis process. ${ }^{[16-18]}$ Therefore, the impact of the electron beam needs to be minimized to correctly interpret the in situ photocatalytic silver deposition experiments. The direct electron beam induced metal deposition from an aqueous $\mathrm{AgNO}_{3}$ solution was assessed by scanning the electron beam over $\mathrm{ZnO}$ crystals submersed in a $10 \mathrm{mM}$ aqueous $\mathrm{AgNO}_{3}$ solution through a $50 \mathrm{~nm}$ thick $\mathrm{Si}_{3} \mathrm{~N}_{4}$ window without any $\mathrm{UV}$ illumination. The results of this experiment are depicted in Figure 3. Whereas the initial overview image (Figure 3a) does not show any signs of silver nanoparticle deposition on the $\mathrm{ZnO}$ crystals, a first magnified image (Figure 3b) clearly reveals the presence of metallic silver nanostructures at the top of the crystals, induced by locally focusing the electron beam. Continued irradiation causes additional growth of the existing silver nanostructures up to several micrometers in size. This process is clearly observed in Figure $3 c$ and d, displaying SEM images after 40 and 
This is the postprint version of the article published as Part. Part. Syst. Charact., 33: 412-418. doi:10.1002/ppsc.201600037

\section{WILEY-VCH}

80 seconds of continuous scanning electron micro-imaging. After these series of magnified images, an overview image was taken of the initial field of view (FOV) (Figure 3e). The dashed square highlights the presence of a light gray area on the $\mathrm{Si}_{3} \mathrm{~N}_{4}$ window which corresponds to the reduced FOV used to image in Figure 3 b-d. A closer look at the regions around the $\mathrm{ZnO}$ crystal in the magnified images (Figure 3b-d) reveals the gradual appearance of silver deposits on the $\mathrm{Si}_{3} \mathrm{~N}_{4}$ window. ${ }^{[17,18]}$ In an additional experiment, the electron beam was deliberately focused in spot mode onto the $\mathrm{ZnO}$ crystal depicted in Figure $3 \mathrm{f}$. The red cross in the schematic representation indicates the electron beam position. In this case an even more extended and branched silver structure is formed at the location of the electron beam. These initial liquid cell experiments in absence of UV illumination clearly show the ability of an electron beam to induce metallic silver deposition from a dilute aqueous $\mathrm{AgNO}_{3}$ solution used for photodeposition experiments. This process needs to be minimized to avoid interference with in situ photodeposition studies. An indication of the electron beam impact can be obtained by calculating the photon-to-electron ratio for the in situ experiment. As the photocatalyst is irradiated with $50 \mu \mathrm{W} . \mathrm{cm}^{-2}$ of $365 \mathrm{~nm}$ UV light during the $120 \mathrm{~s}$ movie, approximately $1.1 \cdot 10^{16}$ photons reach the sample FOV $\left(32.8 \times 32.8 \mu \mathrm{m}^{2}\right)$. In order to obtain sufficiently resolved SEM images of the silver photodeposition, and this at reasonable frame rates, a pixel dwell time of 10 $\mu$ s and a $786 \times 512$ image size have been selected in combination with a $20 \mathrm{kV}$ acceleration voltage and spot size 3. This results in a frame rate of $0.25 \mathrm{~Hz}$ and yields a current of $180 \mathrm{nA}$. Hence, during the acquisition of a $120 \mathrm{~s}$ movie, approximately $1.4 \cdot 10^{11}$ electrons reach the sample FOV $(43.5 \times 29$ $\mu \mathrm{m}^{2}$ ). Based on this, the photon-to-electron ratio for the applied experimental conditions can be calculated to exceed $8 \cdot 10^{4}$. However, this is merely an estimation of the photon-to-electron flux in the sample, as interaction of the electron beam with the liquid contained sample is complex. Besides electron scattering and absorption resulting in a decreased amount of electrons effectively reaching the $\mathrm{ZnO}$ particle, inelastic scattering and the creation of hydrated electrons result in additional electrons 
This is the postprint version of the article published as Part. Part. Syst. Charact., 33: 412-418. doi:10.1002/ppsc.201600037

\section{WILEY-VCH}

reaching the $\mathrm{ZnO}$ surface. ${ }^{[20]}$ Additionally, the effectiveness with which electrons and photons lead to metal deposition needs to be considered. An in depth investigation into these phenomena is not trivial and falls outside the scope of the current study, but will be necessary if detailed quantitative analysis of integrated experiments is required.

\section{In situ silver photodeposition}

After determining the suitable imaging conditions, the first photocatalytic experiment was performed inside the SEM. ZnO crystals were drop casted from an aqueous suspension onto the $\mathrm{Si}_{3} \mathrm{~N}_{4}$ window, and after drying, the liquid cell was assembled containing $50 \mu \mathrm{l}$ of an aqueous $10 \mathrm{mM} \mathrm{AgNO}_{3}$ solution and properly sealed (see Supporting Information for a more detailed explanation). After mounting the liquid cell onto the SEM, a 120 seconds movie was acquired with the conditions as described above (see Supporting Movie S1).

Figure 4a shows the first frame of the SEM movie, after which UV irradiation was initiated. Two crystals of interest are analyzed in depth, i.e. the central vertically oriented dumbbell crystal and the horizontally oriented dumbbell crystal at the top center of the image, both indicated by white squares. Magnifications of these crystals of interest are shown after $0 \mathrm{~s}, 40$ s, $80 \mathrm{~s}$ and $120 \mathrm{~s}$ of UV irradiation in Figure $4 \mathrm{~b}$-e and Figure $4 \mathrm{f}-\mathrm{i}$ respectively. The full image obtained after 120 seconds is shown in Figure 4j. Additionally, after acquiring the movie the two crystals of interest were imaged in more detail as is shown in Figure 4k and 41. These images are obtained independently from the movie and are aimed at providing more detailed information on the size, number and location of the silver nanoparticles formed at the $\mathrm{ZnO}$ surface.

From Figure 4b, taken before the UV irradiation was started, it is evident that some silver deposition has already occurred at the top left edge of the crystal. This local deposit was caused by focusing the electron beam on this particular location prior to the movie acquisition. Over the course of the movie, photo-induced silver dendrite growth is observed to continue at 
This is the postprint version of the article published as Part. Part. Syst. Charact., 33: 412-418. doi:10.1002/ppsc.201600037

\section{WILEY-VCH}

this silver deposit which acts as an efficient electron sink (Figure 4 b-e). Additionally, the photodeposition leads to silver nanoparticles deposited at the $\mathrm{ZnO}$ crystal edges (Figure 4k).

Also for the second crystal the SEM focusing prior to the photodeposition experiment leads to some silver nanoparticle depositions however this crystal does not show the subsequent formation of extended silver dendrite structures (Figure $4 \mathrm{f}-\mathrm{i}$ ). Silver photodeposition mainly leads to nanoparticle formation predominantly located at the crystals' edges. This deposition can be nicely tracked over the course of the movie and the image acquired afterwards (Figure 41) clearly shows the size and shape of these metal nanoparticles.

The background in Figure $4 \mathrm{a}$ and $4 \mathrm{j}$ is inhomogeneous. Whereas the left part is light gray, the right part is darker gray and both areas are separated by a sharp interface. This difference can be explained by the difference in media present in both areas. Whereas $\mathrm{ZnO}$ particles at the left side are in a gaseous environment, as indicated by the increased imaging depth, the particles at the right side of the image are still submersed in the reagent solution. This color assignment is opposite to what was observed earlier in Figure $2 \mathrm{~d}$ and is attributed to the use of the GSED detector in the liquid cell experiment. With the GSED detector, imaging samples at atmospheric pressure (Figure 2c) typically leads to a gray background as a result of the increased environmental pressure in the sample holder; this in contrast to the dark background obtained with other detectors (Figure $2 \mathrm{a}-\mathrm{b}$ ). Furthermore, the interface between the gaseous environment and the liquid moves towards the right during the experiment, due to the intrinsic oxygen generation by the photocatalytic reaction (Equation 1 and 2).

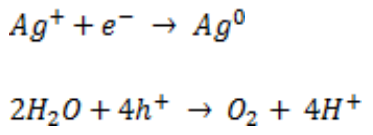


This is the postprint version of the article published as Part. Part. Syst. Charact., 33: 412-418. doi:10.1002/ppsc.201600037

\section{WILEY-VCH}

This local oxygen accumulation does, however, not seem to hamper further observation of the photodeposition process as continuous growth of Ag nanoparticles at the left part of the image is still visible. This observation can be explained by a residual aqueous film that surrounds the $\mathrm{ZnO}$ photocatalysts. Since gas formation is inherent to this photocatalytic experiment, further adaptation of the wet sample holder design could be considered to minimize the accumulation of air pockets underneath the $\mathrm{Si}_{3} \mathrm{~N}_{4}$ window.

Another important observation at the left part of the image is the gradual appearance of whitish spots which can only be linked to silver nanoparticle formation at the $\mathrm{Si}_{3} \mathrm{~N}_{4}$ window.

This is in agreement with literature reports on the characterization of in situ metal nanoparticle growth on $\mathrm{Si}_{3} \mathrm{~N}_{4}$ windows under electron beam irradiation in scanning or transmission electron microscopy. ${ }^{[16,18]}$ These spots were not observed before in our lab when studying the silver photodeposition in a regular optical microscope (Figure S2) and they do not appear in the area where the $\mathrm{Si}_{3} \mathrm{~N}_{4}$ window is still fully wetted by the aqueous silver nitrate solution. It is thus very likely that the local silver reduction by the scanning electron beam leads to this nanoparticle formation. In the residual thin aqueous film, present at the left hand side of the image, these nanoparticles are trapped whereas at the right hand side, the nanoparticles seem to be efficiently removed from the window due to gravity and convection. Note that in Figure $3 \mathrm{~b}-\mathrm{d}$, where the effect of the electron beam on a $\mathrm{ZnO}$ photocatalyst was evaluated, also similar silver nanoparticle deposits at the $\mathrm{Si}_{3} \mathrm{~N}_{4}$ window can be observed. In this reduced field of view, the local electron dose was much higher than in this experiment, resulting in silver nanoparticles which were not (efficiently) removed by the surrounding liquid.

Clearly, when the electron beam passes through the $\mathrm{Si}_{3} \mathrm{~N}_{4}$ window and interacts with the liquid, a complex combination of phenomena occurs simultaneously. Physically, the electron 
This is the postprint version of the article published as Part. Part. Syst. Charact., 33: 412-418. doi:10.1002/ppsc.201600037

\section{WILEY-VCH}

beam can induce convection which is caused by the transfer of momentum and heat from the electron beam to the system. ${ }^{[15,19]}$ Chemically, the electron beam can create ions, free radicals and hydrated electrons, which can subsequently lead to secondary chemical reactions. ${ }^{[20]}$ Therefore, it is important to mention that it is not yet possible to straightforwardly quantify this kind of in situ photocatalytic experiments as the individual physical and chemical processes initiated by the electron beam are not yet fully understood. ${ }^{[21]}$

\section{Conclusion}

The novel integrated light- and electron microscope is successfully applied in combination with a liquid cell to visualize silver nanostructure photodeposition on $\mathrm{ZnO}$ crystals in real time inside the vacuum conditions of the SEM chamber. Initially, the imaging quality obtained with different detectors through a $50 \mathrm{~nm}$ thick $\mathrm{Si}_{3} \mathrm{~N}_{4}$ window and the presence of a liquid inside the imaging cell was checked. Further, we observed that the electron beam has a non-negligible contribution to the silver deposition from a $\mathrm{AgNO}_{3}$ solution. Nevertheless, the described research is a first step towards the real time investigation of the structure-activity relationship of dumbbell-shaped $\mathrm{ZnO}$ crystals and other photocatalysts. Here the silver cocatalyst photodeposition can act as a probe reaction for determining reduction hotspots at the photocatalytic surface. There is clearly still room to further optimize the experimental conditions. A deeper investigation into different imaging conditions is needed in order to reduce the impact of the electron beam and an improved liquid cell design might reduce the formation of air pockets underneath the $\mathrm{Si}_{3} \mathrm{~N}_{4}$ window. In general, a more thorough understanding and quantification of the microscale processes which are induced by the highly energetic electron beam is necessary. 
This is the postprint version of the article published as Part. Part. Syst. Charact., 33: 412-418. doi:10.1002/ppsc.201600037

\section{WILEY-VCH}

Ultimately, this line of research will lead to extremely accurate and insightful information on the structure-activity relationship of varying optically active materials under realistic conditions, i.e. atmospheric pressure and even submersed in liquid. ${ }^{[22]}$ A direct extension of the research described in this paper would be the observation of different dendrite growth rates on distinct crystallographic features, e.g. crystal edges or defects. Further optimization of the liquid cell will moreover allow photocatalytic performance studies of nanostructured materials by means of fluorogenic reactions, revealing the structure-activity relationship with super resolution precision. Clearly, the developed integrated approach is superior to the commonly applied bulk experiments, since indirect measurements only provide ensemble averaged information and fail to capture the underlying molecular processes.

\section{Supporting Information}

Supporting Information is available from the Wiley Online Library or from the author.

\section{Acknowledgements}

We acknowledge financial support from the Research Foundation-Flanders (FWO, Grant G.0962.13, G.0B39.15 and G.0197.11, postdoctoral fellowship to E.D. and K.P.F.J.), KU Leuven Research Fund (C14/15/053, OT/12/059), the Hercules foundation (HER/11/14), Belgian Federal Science Policy Office (IAP-VII/05). The research leading to these results has received funding from the European Research Council under the European Union's Seventh Framework Programme (FP/2007-2013) / ERC Grant Agreement n. [307523], ERC-Stg

LIGHT to M.B.J.R. E.D. and J.V.L. contributed equally to this work.

Received: ((will be filled in by the editorial staff))

Revised: ((will be filled in by the editorial staff)) Published online: ((will be filled in by the editorial staff)) 
This is the postprint version of the article published as Part. Part. Syst. Charact., 33: 412-418. doi:10.1002/ppsc.201600037

\section{WILEY-VCH}

[1] D. Chatterjee and S. Dasgupta, J. Photochem. Photobiol. C: Photochem. Rev. 2005, 6, 186.

[2] T. Tachikawa, S. Yamashita and T. Majima, J. Am. Chem. Soc. 2011, 133, 7197.

[3] P. Chen, X. Zhou, H. Shen, N. M. Andoy, E. Choudhary, K.-S. Han, G. Liu and W. Meng, Chem. Soc. Rev. 2010, 39, 4560.

[4] J. B. Sambur and P. Chen, Ann. Rev. Phys. Chem. 2014, 65, 395.

[5] K. G. M. Laurier, M. Poets, F. Vermoortele, G. D. Cremer, J. A. Martens, H. Uji-i, D. E. De Vos, J. Hofkens and M. B. J. Roeffaers, Chem. Comm. 2011, 48, 1559.

[6] S. C. Chan and M. A. Barteau, Langmuir 2005, 21, 5588.

[7] M. Maicu, M. C. Hidalgo, G. Colón and J. A. Navío, J. Photochem.Photobiol. A: Chem. 2011, 217, 275 .

[8] S. Dunn, S. Sharp and S. Burgess, Nanotechnolgy 2009, 20, 115604.

[9] Y. Matsumoto, S. Ida and T. Inoue, J. Phys. Chem. C 2008, 112, 11614.

[10] C. Pacholski, A. Kornowski and H. Weller, Angew. Chem. 2004, 116, 4878.

[11] N. Liv, I. Lazic, P. Kruit and J. P. Hoogenboom, Ultramicroscopy 2014, 143, 93.

[12] N. Liv, A. C. Zonnevylle, A. C. Narvaez, A. P. J. Effting, P. W. Voorneveld, M. S. Lucas, J. C. Hardwick, R. A. Wepf, P. Kruit and J. P. Hoogenboom, PLoS ONE 2013, 8, e55707.

[13] A. C. Zonnevylle, R. F. C. Van Tol, N. Liv, A. C. Narvaez, A. P. J. Effting, P. Kruit and J. P. Hoogenboom, J. Microsc. 2013, 252, 58.

[14] K. L. Klein, I. M. Anderson and N. De Jonge, J. Microsc. 2011, 242, 117.

[15] N. de Jonge and F. M. Ross, Nat. Nano 2011, 6, 695.

[16] E. U. Donev, G. Schardein, J. C. Wright and J. T. Hastings, Nanoscale 2011, 3, 2709. 
This is the postprint version of the article published as Part. Part. Syst. Charact., 33: 412-418. doi:10.1002/ppsc.201600037

\section{WILEY-VCH}

[17] V. Halka, M. J. Schmid, V. Avrutskiy, X. Ma and R. Schuster, Angew. Chem. Int. Ed. 2011, 50, 4692 .

[18] H. Zheng, R. K. Smith, Y.-W. Jun, C. Kisielowski, U. Dahmen and A. P. Alivisatos, Science 2009, 324, 1309.

[19] L. D. Marks and J. P. Zhang, Ultramicroscopy 1992, 41, 419.

[20] E. R. White, M. Mecklenburg, S. B. Singer, S. Aloni and B. C. Regan, Appl. Phys. Expr. 2011, 4, 055201.

[21] E. Jensen, C. Kobler, P. S. Jensen and K. Molhave, Ultramicroscopy 2013, 129, 63.

[22] H. Yuan, E. Debroye, K. P. F. Janssen, H. Naiki, C. Steuwe, G. Lu, M. Moris, E. Orgiu, H. Uji-i, F. De Schryver, P. Samorí, J. Hofkens and M. B. J. Roeffaers, J. Phys. Chem.Lett. 2016, 7, 561. 
This is the postprint version of the article published as Part. Part. Syst. Charact., 33: 412-418. doi:10.1002/ppsc.201600037

\section{WILEY-VCH}

A)

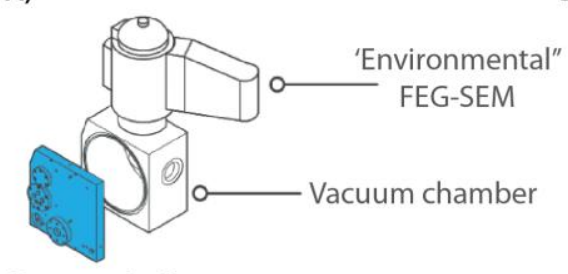

Purpose built

vacuum door
B)

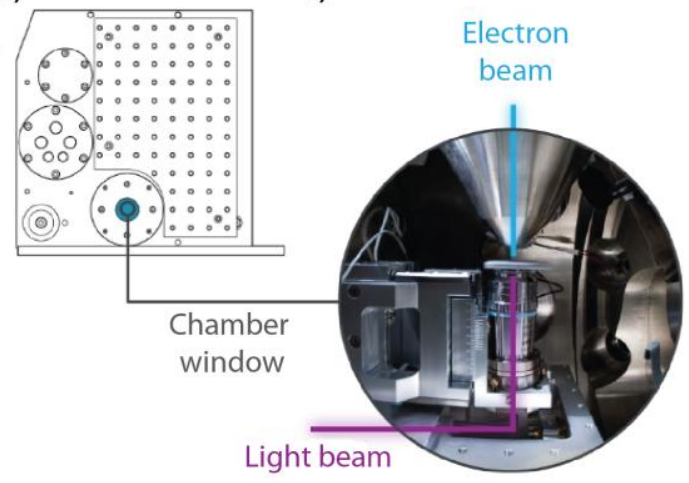

Light beam

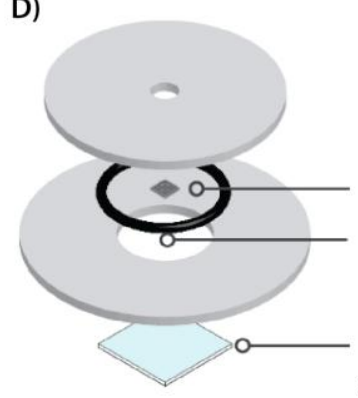

$$
\mathrm{S}_{3} \mathrm{~N}_{4}
$$
window

Sample chamber

Glass

coverslide

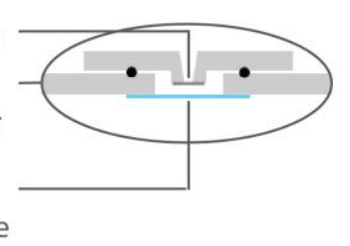

Figure 1. The integrated light- and electron microscope used in these experiments is equipped with (a) a customized chamber door (Delmic BV) holding (b) an optically transparent window. This chamber window allows $365 \mathrm{~nm}$ UV light from the outside to reach the (c) high NA objective lens inside the vacuum chamber, guiding the light onto the field of view that is being imaged by SEM. In order to enable the in situ observation of the photocatalytic silver deposition, (d) a dedicated sample holder has been developed. 
This is the postprint version of the article published as Part. Part. Syst. Charact., 33: 412-418. doi:10.1002/ppsc.201600037

\section{WILEY-VCH}

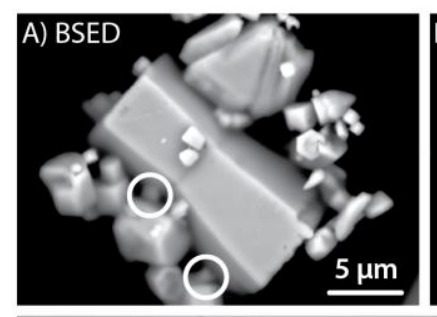

D)

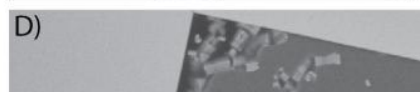

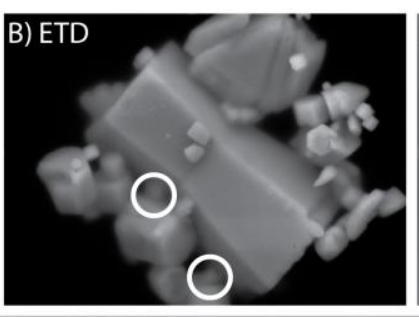
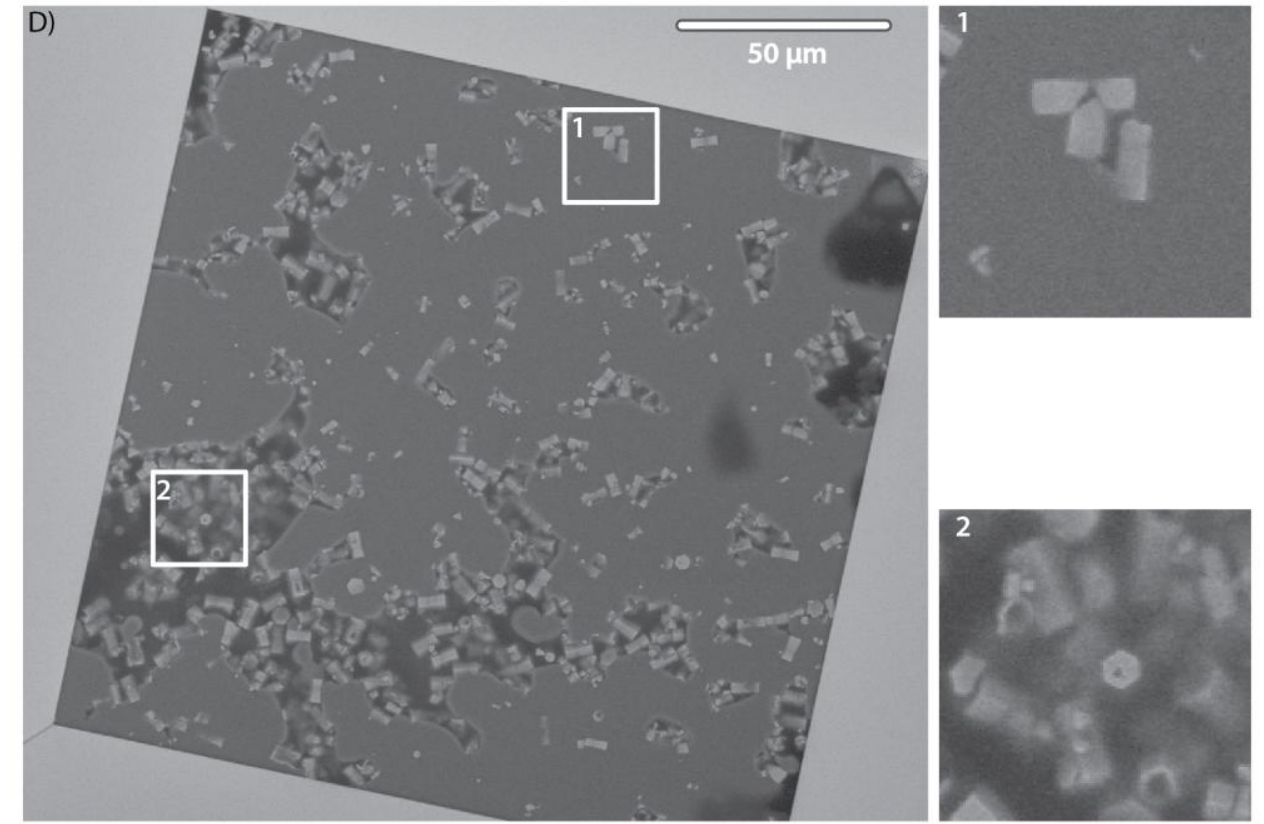

Figure 2. SEM images of ZnO particles obtained with a (a) BSED, (b) ETD and (c) GSED (2 mbar) to demonstrate resolution differences when imaging through a $50 \mathrm{~nm}$ thick $\mathrm{Si}_{3} \mathrm{~N}_{4}$ window at $20 \mathrm{kV}$ acceleration voltage and Spot Size 4. The gray circles highlight structures revealing resolution in depth. The images are ordered according to decreasing resolution. (d) Influence of the presence of liquid on the signal-to-noise ratio during SEM imaging with an ETD in an inadequately assembled liquid cell. 
This is the postprint version of the article published as Part. Part. Syst. Charact., 33: 412-418. doi:10.1002/ppsc.201600037

\section{WILEY-VCH}
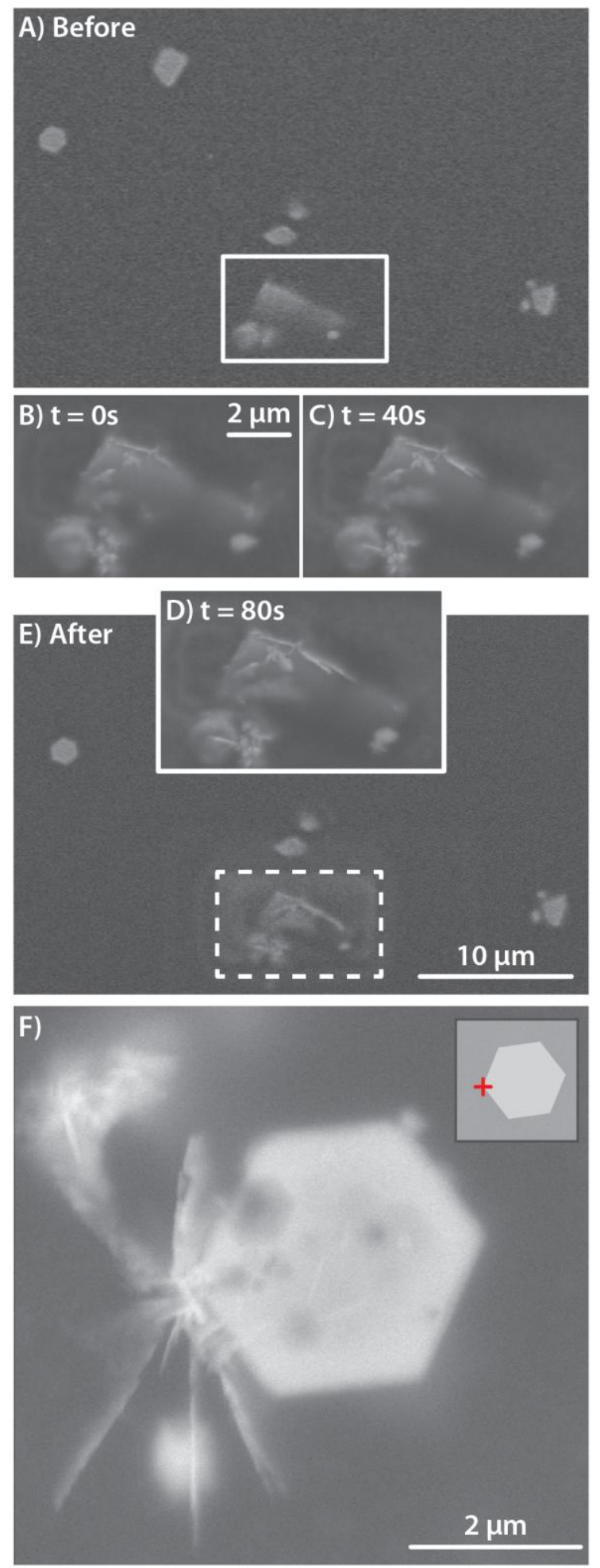
This is the postprint version of the article published as Part. Part. Syst. Charact., 33: 412-418. doi:10.1002/ppsc.201600037

\section{WILEY-VCH}

Figure 3. SEM images of electron beam induced silver deposition recorded with an ETD. (a) Overview image of the initial stage of $\mathrm{ZnO}$ crystals in the liquid cell. Magnified SEM micrographs of two crystals after (b) $0 \mathrm{~s}$, (c) $40 \mathrm{~s}$ and (d) $80 \mathrm{~s}$ of continuous electron beam irradiation, showing metallic silver deposition on the $\mathrm{ZnO}$ crystals. (e) An SEM micrograph of the same FOV as shown for the initial stage, suggesting the presence of silver deposition on the $\mathrm{Si}_{3} \mathrm{~N}_{4}$ window. (f) BSED image of the silver deposition induced by the electron beam in spot mode focused at the corner of the $\mathrm{ZnO}$ particle as indicated by the red cross in the schematic representation. 
This is the postprint version of the article published as Part. Part. Syst. Charact., 33: 412-418. doi:10.1002/ppsc.201600037

\section{WILEY-VCH}
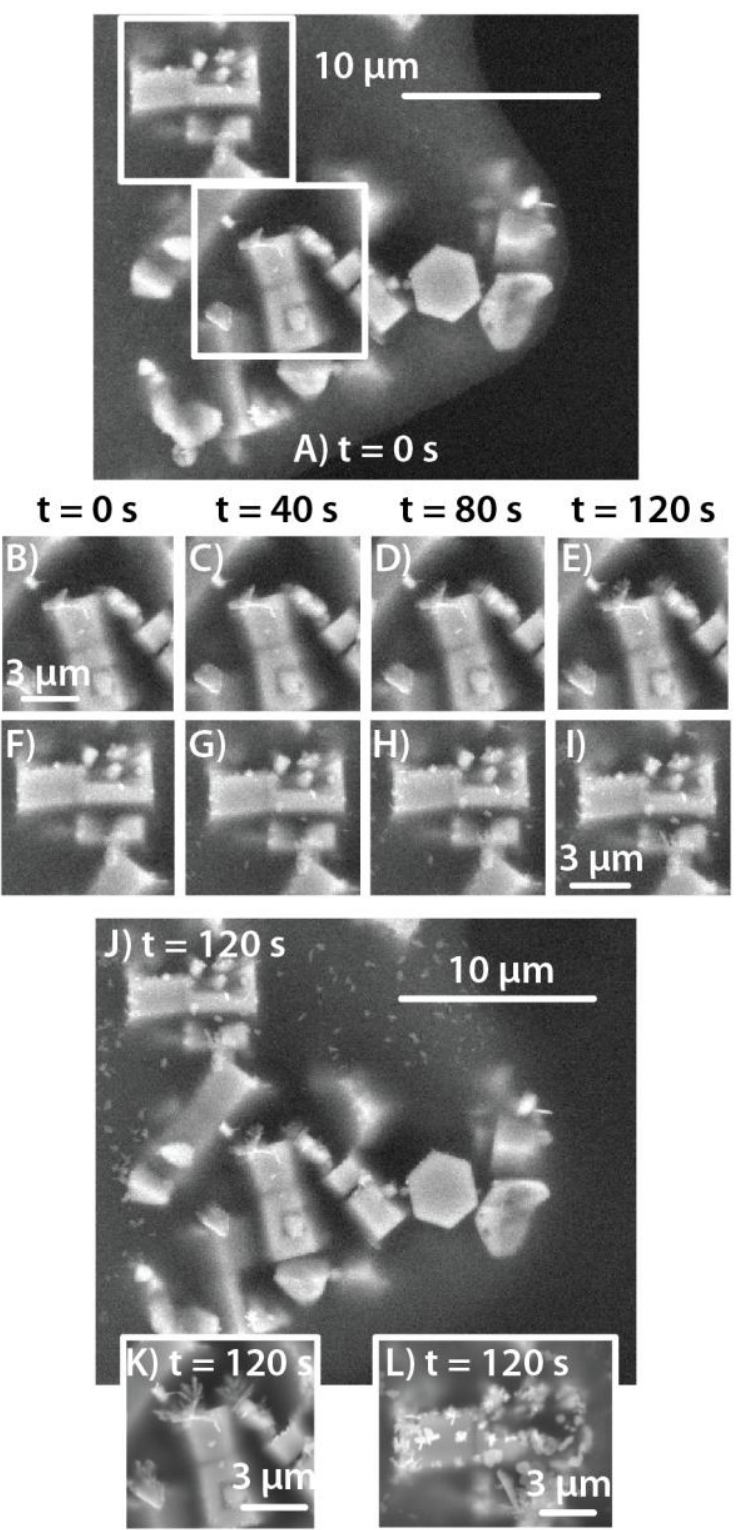

Figure 4. Scanning electron micrographs of (a) the first and (j) the last frame of a $120 \mathrm{~s}$ movie of the in situ photo-induced silver metal deposition on $\mathrm{ZnO}$ dumbbell-shaped crystals. (b-e) and (f-i) depict enlarged images of two crystals of interest after $0 \mathrm{~s}, 40 \mathrm{~s}, 80 \mathrm{~s}$ and $120 \mathrm{~s}$ of UV light illumination. (k) and (l) show SEM images of both crystals after the in situ experiment, acquired with optimized imaging settings. All images are obtained using the GSED. 
This is the postprint version of the article published as Part. Part. Syst. Charact., 33: 412-418. doi:10.1002/ppsc.201600037

\section{WILEY-VCH}

